\title{
Intramuscular gold decreases cytokine expression and macrophage numbers in the rheumatoid synovial membrane
}

\author{
Ghada Yanni, M Nabil M R Farahat, Robin N Poston, Gabriel S Panayi
}

\begin{abstract}
Objectives-Cytokines, released from mononuclear cells (MNC) are mediators of joint destruction in rheumatoid arthritis (RA). The mechanisms of action of gold salts used in the treatment of RA are unknown. The aim of this study was to investigate cytokine expression and intensity of MNC infiltrate in the RA synovial membrane (SM) following treatment with sodium aurothiomalate (SAT).
\end{abstract}

Methods-Sequential blind needle biopsies were obtained at entry into the study and at two and 12 weeks after the start of SAT therapy in 10 patients with active RA. SMs were stained with a panel of monoclonal antibodies to assess cytokine expression (IL-1 $\alpha$, IL-1 $\beta$, TNF- $\alpha$, IL-6, and GM-CSF).

Results-There was a significant decrease in IL-1 $\alpha$, IL-1 $\beta$, IL-6 and TNF- $\alpha$ expression 12 weeks after treatment $(\mathrm{p}<0.004, \mathrm{p}<0.002, \mathrm{p}<0.009$ and $\mathrm{p}<0.004$ respectively). This was noted in the lining layer, the perivascular aggregates and the connective tissue areas. Detailed examination of the MNC infiltrate showed a significant reduction in inflammatory monocytes (MONO) in the lining layer at two weeks $(p<0.03)$. A decrease in the number of CD68+ macrophages (MAC) was noted in the perivascular and connective tissue areas at 12 weeks. No significant changes were observed in the number of $T$ and $B$ cells and blood vessels.

Conclusion-The results suggest that gold may suppress RA disease activity by diminishing MONO and MAC numbers and consequently monokine production in the SM.

(Ann Rheum Dis 1994; 53: 315-322)

Rheumatoid arthritis (RA) is a chronic immune-mediated inflammatory disease of unknown aetiology. Its pathogenesis is predicated on $\mathrm{T}$ cell and MONO/MAC activation with the release of a number of monokines such as interleukin 1 (IL-1) and tumour necrosis factor alpha (TNF- $\alpha$ ), which secondarily lead to the release of cytokines from other cells such as synoviocytes. ${ }^{1}$ Collectively, the release of these and other inflammatory mediators as well as the activation of synoviocytes, MONOs/MACs, chondrocytes and osteoclasts bring about the inflammatory and destructive changes which are characteristic of the disease. A crucial role for these pathogenetic events is the accumulation of MONOs from the circulation. Bone marrow grafting experiments in mice have shown that the resident type A cells of the synovial lining layer are of bone marrow origin. ${ }^{2}$ After entry into tissues, MONOs mature into MACs and the differentiation steps involved have been studied in vitro and followed both in vivo and in vitro by appropriate monoclonal antibodies (mAb). Sorg et al have developed a series of monoclonal antibodies which mark the early acute inflammatory MONO $(27 \mathrm{E} 10)^{3}$ and the anti-inflammatory MAC ( RM 3/1). ${ }^{4}$ There is increasing evidence that the function of MONO/MAC is dependent on the stage of differentiation reached by these cells. Thus MONO are potent producers of proinflammatory monokines such as IL-1, whereas optimal production of the IL-1 receptor antagonist (IL-1 ra) requires that the MONO be matured to MAC by in vitro culture in the presence of immobilised IgG, as a form of model immune complexes, and granulocyte/ macrophage colony stimulating factor (GMCSF). ${ }^{56}$ Since inflammatory events may be regulated by the balance between proinflammatory cytokines, such as IL-1, and soluble inhibitors, such as IL-1ra, the shift of this balance to the latter could offer therapeutic benefits to the patient. Indeed, IL-1ra has been shown to be effective treatment for experimental models of arthritis. ${ }^{7}$

The treatment of RA with SAT is still widespread despite a variable therapeutic response, serious side effects and lack of knowledge of its mode of action. ${ }^{8}$ Little attention has been paid to the changes which occur in the RA SM following the introduction of SAT. In previous studies, a reduction in the $\mathrm{T}$-cell infiltrate was noted ${ }^{90}$ but only after six months of treatment by which time therapeutic benefit is well established. Other measurements of inflammatory capacity, such as decreased HLA-DR expression, decreased thickness of the synovial lining layer and reduction in the number of blood vessels, have proved equally disappointing. ${ }^{11}$

So called disease modifying drugs (DMARDs), such as SAT, have been used for the treatment of RA on empirical grounds; 
consequently, their mode of action is still uncertain and is based mainly on in vitro work. This is particularly true for SAT for which such diverse activities as inhibition of MONO accessory function in $\mathrm{T}$ lymphocyte activation, inhibition of production of rheumatoid factor production, interference with the antigen presenting function of HLA molecules and inhibition of endothelial cell proliferation, have been described $;^{8}$ however, little or no evidence has been produced on the relevance of these findings to its in vivo mode of action. Recently, it has been shown that SAT will accelerate the in vitro maturation of MONO to MAC with a concomitant decrease in IL-1 production. ${ }^{12}{ }^{13}$ Thus there is now the possibility to relate the therapeutic benefit with changes in expression of cytokines and the relative contribution of inflammatory MONO and downregulatory MAC within the synovial cell populations.

We reasoned that if SAT could induce maturation of MONO in the RA SM then there would be decreased production of proinflammatory cytokines as well as a decrease in the numbers of $27 \mathrm{E} 10$ positive monocytes, the former being dependent on the latter. In this study, multiple synovial biopsies were obtained from the knee joints of patients with RA before and at two and 12 weeks following the administration of SAT. Serial changes in cellular composition, with particular reference to MONO and MAC cells, and cytokine expression were examined using immunohistochemistry with appropriate mAb directed against cellular markers and against the inflammatory cytokines IL- 1, TNF- $\alpha$, GM-CSF and interleukin 6 (IL-6).

\section{Patients and methods}

PATIENTS AND TREATMENT PROTOCOL

Ten patients (table 1) with $\mathrm{RA}^{14}$ attending the Rheumatology Unit of Guy's and Lewisham Hospitals were selected for a study comparing the clinical and synovial histological changes observed after the administration of intramuscular SAT or a combination of intramuscular SAT and methylprednisolone. All patients received intramuscular SAT which was given as a $10 \mathrm{mg}$ test dose followed by $50 \mathrm{mg}$ weekly until a total dose of $1.0 \mathrm{~g}$ was reached after which SAT was continued at $50 \mathrm{mg}$ monthly. Five patients received $120 \mathrm{mg}$ of methylprednisolone acetate intramuscularly at 0,4 and 8 weeks of SAT whilst the other five received intramuscular $1 \mathrm{ml}$ normal saline at the same time. Allocation between the two treatment groups was random. ${ }^{15}$ Patients were entered into the study if they required DMARDs and had either persistent synovitis despite non-steroidal anti-inflammatory drugs

Table 1 Characteristics of the patients studied

\begin{tabular}{ll}
\hline Total number & 10 \\
Male:Female & $6: 4$ \\
Mean (SD) age (range) & $64 \cdot 3(35-80)$ years \\
Mean (SD) disease duration (range) & $7 \cdot 4(0 \cdot 25-20)$ years \\
IgM-RF positive (latex) & 9 \\
Nodules & 3 \\
\hline
\end{tabular}

(NSAIDs) for three months or progressive erosions on radiographs and all had Westergren erythrocyte sedimentation rate (ESR) greater than $40 \mathrm{~mm} / \mathrm{h}$. All patients had an obvious knee synovitis. Patients were excluded if they had received previous treatment with gold or were aged less than 16 years or greater than 80 years. Proteinuria, glucocorticoid treatment, (oral or intramuscular) within three months of entry, were further exclusion criteria.

All patients gave their written consent and the study had the approval of the Lewisham and North Southwark District Ethics Committee.

\section{CLINICAL AND LABORATORY ASSESSMENT OF DISEASE ACTIVITY}

Patients were assessed by one rheumatologist at entry into the study and at two and 12 weeks following the administration of SAT. Routine measurements of disease activity included Ritchie articular index, ${ }^{16}$ visual analogue scale for pain (VAS), grip strength (using a folded sphygmanometer cuff inflated to $30 \mathrm{~mm} / \mathrm{Hg}$, three attempts and results expressed as the mean value of both hands). Laboratory assessments included full blood count, ESR in the first hour and rheumatoid factor.

\section{SYNOVIAL BIOPSY}

Synovial samples were obtained from one knee joint of all patients by a blind biopsy technique at 0,2 and 12 weeks using a WilliamsonHolt synovial biopsy needle (Shrimpton and Fletcher Needle Industries, Redditch, Worcestershire, UK) under sterile conditions. Where only one knee was involved, the specimens were obtained from the affected side, when both knees were involved, the biopsy was performed on a side selected at random. Repeat biopsies were performed on the same knee joint. Local anaesthesia using $2 \%$ lignocaine was administered. To facilitate the biopsy procedure, $20 \mathrm{ml}$ of sterile saline were instilled into each joint. Multiple synovial samples (minimum of four) were obtained from the supra-patellar pouch of the knee joint from as wide an area as possible within reach of the needle.

\section{TISSUE PREPARATION AND STAINING}

Synovial specimens were snap frozen within 30 minutes of the biopsy procedure after orientation in optimal temperature cutting compound (OTC) in isopentane cooled in liquid nitrogen. Samples were stored at $-70^{\circ} \mathrm{C}$ until sectioned for immunohistological staining. Frozen samples were embedded in OTC and $5 \mu \mathrm{m}$ sections were cut with a cryostat (Leitz) at $-20^{\circ} \mathrm{C}$. Sequential sections were mounted on gelatine/poly-l-lysine coated slides and dried overnight at room temperature. Sections were fixed in acetone for 20 minutes wrapped in tin foil and stored at $-70^{\circ} \mathrm{C}$ until further use. Cytokines and cellular antigens were determined by an indirect immunoperoxidase technique. ${ }^{17} 18$ The mAb 
used to determine cellular content were UCHT1, OKT4, OKT8, TO15, and EBM11 (anti-CD3, anti-CD4, anti-CD8, anti-CD22 and anti-CD68 respectively, Dako laboratories, Copenhagen, Denmark), UCHM1 (anti-CD14, gift of $\mathrm{Dr} \mathrm{N}$ Hogg, ICRF, London), 27E10 and RM3/1 (early MONO and late MAC markers respectively, gift of Professor C Sorg, Germany). FVIII (Dako) was used to stain endothelial cells. The mAb used to determine cytokine expression were anti-IL-1 $\alpha$ (gift of Dr R Thorpe, NIBSC, Potters Bar), anti-IL-1 $\beta$ (gift of Dr D Boraschi, Italy), anti-IL-6 (gift of Dr T Hirano, Osaka, Japan), anti-TNF- $\alpha$ (gift of Dr H A Cousin, Roussel, Romainville, France) and anti-GMCSF (gift of Dr K Ruedi, Sandoz, Basel, Switzerland).

Briefly, the primary mAbs, at appropriate dilutions in phosphate buffer saline (PBS), were incubated on synovial tissue sections in a humidified chamber at room temperature for two hours for cytokine staining and for 45 minutes for cellular antigen staining, after an initial incubation for 120 minutes with a 1:20 dilution of normal rabbit serum. The excess $\mathrm{mAb}$ was removed by washing with PBS. After absorption with human liver powder diluted at $1: 20$ in normal human serum, the second antibody, biotinylated rabbit anti-mouse IgG (Dako Laboratories, Copenhagen, Denmark) diluted in PBS at 1:300, was added and sections incubated for 30 minutes. This was followed by washing with PBS and incubation for 45 minutes with avidin-biotin peroxidase complex (ABC Vecta Stain Kit, Vector Laboratories, Ontario, Canada). The sections were developed in a solution of diaminobenzidine tetrahydrochloride $(0.7 \mathrm{mg} / \mathrm{ml})$, and counterstained with haematoxylin. Finally, sections were dehydrated by transferring through alcohol and CNP30 and mounted in DPX.

Negative control staining was performed on all synovial specimens studied. This was identical except that incubation with the primary $\mathrm{mAb}$ was omitted. No staining was noted in these sections. Tonsil tissue was used as a positive control. Other controls included MOPC21, a non-immune mouse IgG1 myeloma protein used at equivalent protein concentration with a similar isotype to the cytokine monoclonal antibodies used.

All comparisons between specimens were made with data derived from the same staining run.

CONFIRMATION OF CYTOKINE IMMUNOREACTIVITY

The specificity of the cytokine monoclonal antibodies has been extensively studied and demonstrated by the providers of these proteins. Anti-TNF- $\alpha$ (personal communication from MA Cousin, Roussel) was obtained after fusion of immunised BALB/c spleen cells with SP2/0-Ag14 myeloma cells. Partially purified murine immunoglobulins (sodium sulphate precipitated from ascitic fluid dissolved and dialysed in PBS) was used. This antibody did bind to $\mathrm{r}-\mathrm{Hu}-\mathrm{TNF}-\alpha$ coated on ELISA plates and neutralised $r-\mathrm{Hu}-\mathrm{TNF}-\alpha$ cytotoxic activity an L929 cells. The specificity of the other cytokine monoclonal antibodies has been documented in published manuscripts; IL- $1 \alpha,{ }^{19}$ IL- $1 \beta,{ }^{20}$ GM-CSF ${ }^{21}$ and IL-6. ${ }^{22}$

\section{MICROSCOPIC EVALUATION}

Evaluation was undertaken in a minimum of four different synovial tissue samples for each patient at each time point. Cytokine expression and intensity of cellular infiltrate were assessed in three areas of the synovial membrane: (1) lining layer, (2) perivascular lymphoid aggregate, where there was a cellular infiltrate of at least five cells in depth surrounding a central vessel, (3) connective tissue, where mononuclear cells were randomly arranged throughout without the formation of discrete perivascular aggregates.

All microscopic evaluations were performed by one observer (NF) who was 'blind' to the names of the patients and time of biopsy. Furthermore, to rule out intra-observer variation, samples from five patients were read on three different occasions. No statistically significant differences were observed between the three readings. Samples were also assessed by another observer (GY); the results agreed with the first observer.

\section{CYTOKINE STAINING}

Cytokine expression was assessed by estimating the intensity of staining and the number of the positively staining cells in the three areas defined above in a minimum of four biopsy samples at each time point for each patient. The intensity of staining was estimated by devising a visual analogue scale (VAS) from $0-15 \mathrm{~cm}$, where 0 indicated no staining at all and 15 maximal staining. All sections were examined and results were expressed as a mean. For the number of positively staining cells, a total of 200 cells was examined in each of the areas and the number of positively staining cells was expressed as a percentage. Positivity was noted when complete staining of the cell was observed.

\section{MONONUCLEAR CELLULAR INFILTRATE}

The number of cells staining positively for a particular cell marker was counted out of a total of 200 cells in each of the lining layer, perivascular and connective tissue areas and the results expressed as a percentage.

\section{SYNOVIAL LINING LAYER THICKNESS}

Synovial lining layer thickness was estimated by assessing all visible lining layer at a magnification of $\times 400$. The thickness was quantified according to the cell depth. Three random readings per high power field (HPF) were recorded and the results expressed as a mean. 
VASCULAR PROLIFERATION

Vascular proliferation was estimated by counting the number of blood vessels staining with FVIII per HPF at a magnification of $\times 400$ and expressing the results as a mean.

\section{STATISTICS}

Results in the text, figures and tables are expressed as mean (SD). Histological scores at different time points were compared using the Wilcoxon signed rank test.

\section{Results}

Ten patients were entered into this study, six men and four women, with a mean age of 64.3 and mean disease duration of 7.4 years (table 1). Five were treated with intramuscular SAT and another five with a combination of intramuscular SAT and $120 \mathrm{mg}$ of intramuscular depot methylprednisolone acetate.

There was no statistically significant difference between the patients receiving SAT and a combination of SAT and methylprednisolone in the clinical scores, SM cytokine staining and intensity of mononuclear cellular infiltrate, before treatment and two and 12 weeks after the start of SAT. Thus the results from both clinical groups have been combined for this report.

CLINICAL AND LABORATORY MEASUREMENTS Twelve weeks following the start of therapy, there was a significant decrease in VAS and Ritchie articular index and an increase in grip strength (table 2). No changes were observed in haemoglobin and ESR. Clinical and laboratory scores did not improve at two weeks. The results of this clinical study have been published previously. ${ }^{15}$

Table 2 Assessment of disease activity at entry, two weeks and 12 weeks of the study

\begin{tabular}{lcccl}
\hline & Entry & 2 weeks & 12 weeks & $P$ \\
\hline VAS pain $(\mathrm{cm})$ & $6 \cdot 6(1 \cdot 0)$ & $6 \cdot 2(1 \cdot 2)$ & $4 \cdot 5(0 \cdot 8)$ & $<0 \cdot 02$ \\
Ritchie index & $8 \cdot 6(1 \cdot 1)$ & $8 \cdot 0(1 \cdot 6)$ & $4 \cdot 7(3 \cdot 1)$ & $<0 \cdot 005$ \\
Grip strength $(\mathrm{mm} / \mathrm{Hg})$ & $294(99)$ & $303 \cdot 0(81 \cdot 0)$ & $344 \cdot 0(79 \cdot 0)$ & $<0 \cdot 04$ \\
Haemoglobin $(\mathrm{g} \%)$ & $13 \cdot 1(2 \cdot 3)$ & $13 \cdot 0(1 \cdot 9)$ & $12 \cdot 9(1 \cdot 6)$ & NS \\
ESR $(\mathrm{mm} / \mathrm{hr})$ & $43 \cdot 3(33 \cdot 0)$ & $38 \cdot 0(27 \cdot 0)$ & $37 \cdot 4(32 \cdot 0)$ & NS \\
\hline
\end{tabular}

Results expressed as mean (SD). NS = non-significant. $P$ values, differences between week 0 and week 12.
CELLULAR COMPOSITION

Examination of the cellular infiltrate revealed changes in the MONO/MAC population only. CD68+ cells were the most commonly identified MAC in the three areas of the synovium examined. The numbers of 27E10+, CD14+ and $\mathrm{RM} 3 / 1+\mathrm{MONO} / \mathrm{MAC}$ were similar. There was a significant decrease in the number of $27 \mathrm{E} 10$ positively staining $\mathrm{MONO}$ from $18 \cdot 9 \%$ at entry to $12 \cdot 2 \%$ at two weeks and to $9 \cdot 1 \%$ at 12 weeks in the lining layer ( $\mathrm{p}<0.04$ and $\mathrm{p}<0.03$ respectively), table 3 . There was a significant reduction in the number of $\mathrm{CD} 68$ positively staining MACs from $62 \cdot 3 \%$ at entry to $44 \cdot 1 \%$ at 12 weeks in the perivascular areas and from $49.5 \%$ at entry to $38.5 \%$ at 12 weeks in the connective tissue areas $(\mathrm{p}<0.02$ and $\mathrm{p}<0.008$ respectively), table 3. No changes were observed in the percentage of positively staining CD14 and RM3/1 cells. The numbers of CD3+, CD4+, CD8+ and CD22+ cells did not alter.

The number of blood vessels and synovial lining layer thickness did not vary significantly throughout the study period.

\section{CYTOKINE EXPRESSION}

Cytokine expression was estimated by assessing the intensity of staining and by counting the number of positively staining cells. Significant changes were noted, in all areas of the synovium, 12 weeks after the start of therapy compared with entry into the study (fig la-f). No changes were noted at two weeks (data not shown).

In the lining layer (fig 2), there was a significant decrease in the intensity of staining for IL- $1 \alpha$ from 5.0 at entry to 4.2 at 12 weeks (p<0.05), IL-1 $\beta$ from 6.0 to $2.5(p<0.006)$ and IL-6 from 4.2 to $3.8(\mathrm{p}<0.05)$. TNF- $\alpha$ fell from $4 \cdot 3$ to $2 \cdot 0$ but this just failed to reach statistical significance $(p<0.064)$. There was no significant change in the percentage of positively staining cells.

In the perivascular areas (fig 3), there was a significant decrease in the intensity of staining for IL- $1 \alpha$ from 6.8 to $5.2(p<0.01)$, IL-1 $\beta$ from $4 \cdot 1$ to 2 (p<0.01), TNF- $\alpha$ from 3.5 to $1.2(\mathrm{p}<0.05)$ and IL-6 from 3.5 to 1.5 $(p<0.01)$ (fig 3). Furthermore, there was a significant reduction in the number of IL- $1 \alpha$ and IL- 6 positively staining cells, from $12 \%$ to

Table 3 Mononuclear cellular infiltrate, number of blood vessels and lining layer thickness of the synovial membrane at entry, two and 12 weeks of the study

\begin{tabular}{|c|c|c|c|c|c|c|c|c|c|}
\hline & \multicolumn{3}{|l|}{ Lining layer } & \multicolumn{3}{|l|}{ Perivascular } & \multicolumn{3}{|c|}{ Connective tissue } \\
\hline & 0 & 2 & 12 & 0 & 2 & 12 & 0 & 2 & 12 \\
\hline $\begin{array}{l}\text { Mononuc } \\
\text { CD3+ } \\
\text { CD4+ } \\
\text { CD8+ } \\
\text { CD22+ } \\
27 \mathrm{E} 10+ \\
\text { CD14+ } \\
\text { RM1/3 } \\
\text { CD68+ }\end{array}$ & $\begin{array}{l}\text { r cellular infiltrate } \\
\end{array}$ & $\begin{array}{l}\text { Not present } \\
\text { Not present } \\
\text { Not present } \\
\text { Not present } \\
12 \cdot 2(9 \cdot 2)^{\star} \\
17 \cdot 2(11 \cdot 6) \\
19 \cdot 2(22 \cdot 7) \\
61 \cdot 0(19 \cdot 0)\end{array}$ & $\begin{array}{c}9 \cdot 1(9 \cdot 0)^{\star} \\
12 \cdot 6(8 \cdot 5) \\
12 \cdot 1(7 \cdot 1) \\
65 \cdot 9(11 \cdot 5)\end{array}$ & $\begin{array}{r}39 \cdot 5(24 \cdot 3) \\
18 \cdot 6(19 \cdot 6) \\
24 \cdot 7(12 \cdot 2) \\
9 \cdot 1(9 \cdot 5) \\
12 \cdot 5(14 \cdot 9) \\
20 \cdot 8(13 \cdot 2) \\
11 \cdot 0(10 \cdot 1) \\
62 \cdot 3(18 \cdot 8)\end{array}$ & $\begin{array}{l}37 \cdot 8(28 \cdot 7) \\
28 \cdot 4(19 \cdot 1) \\
27 \cdot 5(21 \cdot 2) \\
12 \cdot 7(10 \cdot 6) \\
12 \cdot 4(7 \cdot 2) \\
20 \cdot 5(12 \cdot 3) \\
11 \cdot 0(10 \cdot 1) \\
45 \cdot 8(24 \cdot 5)\end{array}$ & $\begin{array}{l}34 \cdot 8(15 \cdot 8) \\
24 \cdot 3(2 \cdot 9) \\
24 \cdot 0(13 \cdot 2) \\
18 \cdot 0(20 \cdot 0) \\
16 \cdot 4(20 \cdot 0) \\
35 \cdot 9(24 \cdot 3) \\
12 \cdot 0(7 \cdot 9) \\
44 \cdot 1(19 \cdot 6)^{\star}\end{array}$ & $\begin{array}{c}18.3(11.0) \\
24.9(22.0) \\
9.2(6.9) \\
5.9(6.4) \\
8.6(9.8) \\
8.9(6.6) \\
8.2(8.9) \\
49.5(26.4)\end{array}$ & $\begin{array}{c}17 \cdot 7(21 \cdot 7) \\
13 \cdot 9(16 \cdot 0) \\
7.0(4 \cdot 6) \\
6 \cdot 5(8 \cdot 1) \\
10 \cdot 6(13 \cdot 2) \\
13 \cdot 5(15 \cdot 3) \\
15 \cdot 3(24 \cdot 0) \\
38 \cdot 0(21 \cdot 5)\end{array}$ & $\begin{array}{c}19 \cdot 5(15 \cdot 5) \\
21 \cdot 4(23 \cdot 9) \\
6 \cdot 9(4 \cdot 7) \\
4 \cdot 1(5 \cdot 7) \\
5 \cdot 4(5 \cdot 9) \\
12 \cdot 9(7 \cdot 5) \\
11 \cdot 1(13 \cdot 3) \\
30 \cdot 8(12 \cdot 2)^{\star}\end{array}$ \\
\hline Others & & & 0 & & 2 & & 12 & & \\
\hline $\begin{array}{l}\text { Number } \\
\text { Lining lay }\end{array}$ & $\begin{array}{l}\text { essels per HPF } \\
\text { thickness }\end{array}$ & & $\begin{array}{l}7 \cdot 3(4 \cdot 9) \\
8 \cdot 9(4 \cdot 0)\end{array}$ & & $\begin{array}{l}8 \cdot 3(4 \cdot 5) \\
8 \cdot 7(3 \cdot 5)\end{array}$ & & $\begin{array}{l}8 \cdot 6(6 \cdot 0) \\
7 \cdot 0(3 \cdot 0)\end{array}$ & & \\
\hline
\end{tabular}

$0=$ before treatment, $2=$ two weeks after treatment, $12=12$ weeks after treatment.

$\mathrm{HPF}=$ high power field, ${ }^{\star}=$ significant values, results expressed as mean (SD). 
$5 \%(\mathrm{p}<0.04)$ and from $5 \%$ to $0(\mathrm{p}<0.02)$ respectively (fig 3 ).

In the connective tissue area (fig 4 ), there was a significant decrease in the intensity of staining for IL- $1 \alpha$ from 5.2 to $2.8(\mathrm{p}<0.02)$, IL-1 $\beta$ from 3.9 to $1.5(\mathrm{p}<0.004)$, TNF- $\alpha$ from 3.9 to 1 ( $p<0.02)$, IL-6 from 3.8 to 1.8 $(\mathrm{p}<0.05)$ and GM-CSF from 3.5 to 1.8 $(p<0.05)$. Furthermore, there was a significant reduction in the number of IL-1 $\alpha$, and IL-6 positively staining cells, from $14 \%$ to $3 \%(\mathrm{p}<0.04)$ and from $6 \%$ to $2 \%(\mathrm{p}<0.04)$ respectively.

\section{Discussion}

Ten patients with active RA were studied prospectively for 12 weeks after the introduction of SAT or a combination of SAT and intramuscular steroid therapy. SM cytokine expression and intensity of MNC infiltrate were examined at 0,2 and 12 weeks. Clinical improvement was noted in all patients at 12 weeks.

Monokine expression (IL- $1 \alpha, \Pi-1 \beta$, TNF- $\alpha$ and IL-6) was diminished at 12 weeks in most areas of the synovium. There was a significant decrease in the number of $27 \mathrm{E} 10+$ MONOs at two and 12 weeks in the lining layer. CD68+ MACs were reduced at 12 weeks in the perivascular and connective tissue areas. CD14+ MONOs remained unchanged. No significant differences were noted between the patients receiving SAT and a combination of SAT and methylprednisolone in the SM cytokine staining and intensity of MNC infiltrate. These findings may suggest a lack of sensitivity of the methods used or that the early clinical effects of methylprednisolone may be due to effects on cells or cytokines not examined in the present study.

This is the first study to examine cytokine expression in the rheumatoid synovium following treatment. Our results suggest that SAT may alter MONO/MAC function by inhibiting monokine production in the SM and that this reduction may be responsible for the clinical improvement seen in these patients since they occurred at the same time at 12 weeks. In vitro studies show that the inhibitory effect of gold on lymphocyte proliferation is enhanced when MONO numbers are reduced

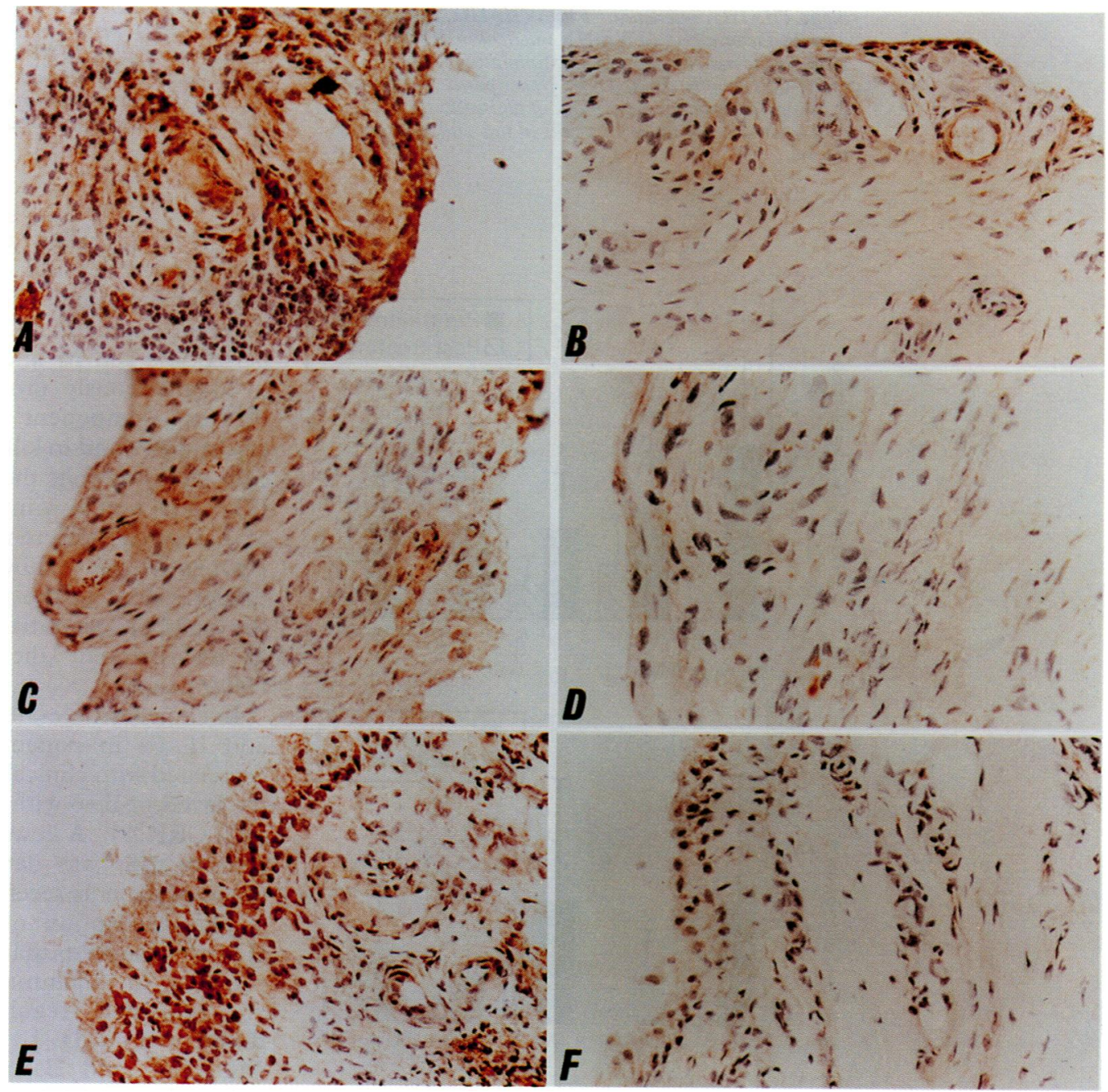

Figure 1 (A) Interleukin-1 $\alpha$ staining in the synovial membrane at entry into the study (magnification $\times 650)$; (B) Interleukin-1 $\alpha$ staining in the synovial membrane 12 weeks after starting sodium aurothiomalate therapy (magnification $\times 650) ;(C)$ Interleukin-1 $\beta$ staining in the synovial membrane at entry into the study (magnification $\times 650) ;(D)$ Interleukin-1 $\beta$ staining in the synovial membrane 12 weeks after starting sodium aurothiomalate therapy (magnification $\times 650$ ); (E) Tumour necrosis factor- $\alpha$ staining in the synovial membrane at entry into the study (magnification $\times 650$ ); (F) Tumour necrosis factor- $\alpha$ staining in the synovial membrane 12 weeks after starting sodium aurothiomalate therapy (magnification $\times 650$ ). 

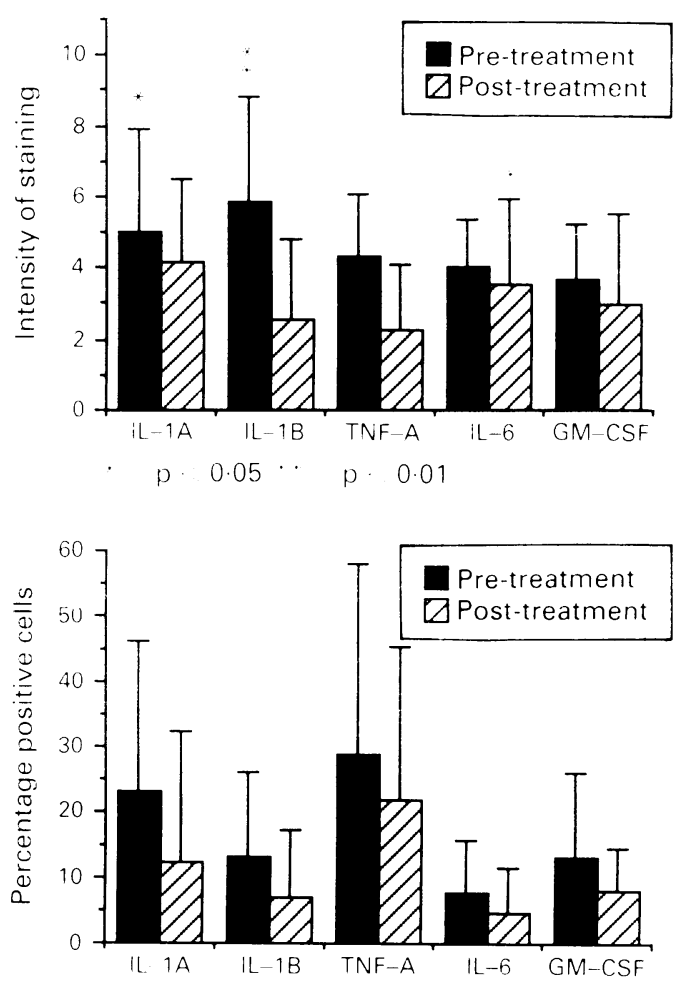

Figure 2 Measurement of the cytokines interleukin-1 alpha (IL-1A), interleukin-1 beta (IL-1B), tumour necrosis factor alpha (TNF-A), interleukin-6 (IL-6) and granulocyte macrophage-colony stimulating factor

(GM-CSF) in the lining layer. Upper panel: intensity of staining; lower panel: percentage of positively staining cells. Post treatment values at 12 weeks in this and subsequent figures.
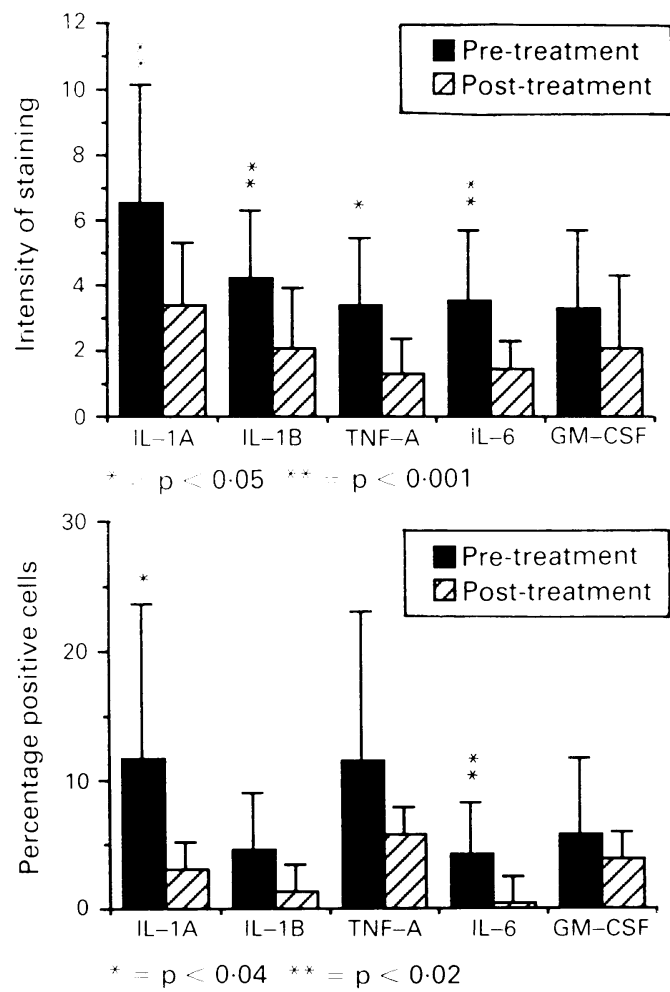

Figure 3 Measurement of the cytokines interleukin-1 alpha (IL-1A), interleukin-1 beta (IL-1B), tumour necrosis factor alpha $(T N F-A)$, interleukin-6 (IL-6) and granulocyte macrophage-colony stimulating factor (GM-CSF) in the perivascular areas. Upper panel: intensity of staining; lower panel: percentage of positively staining cells.
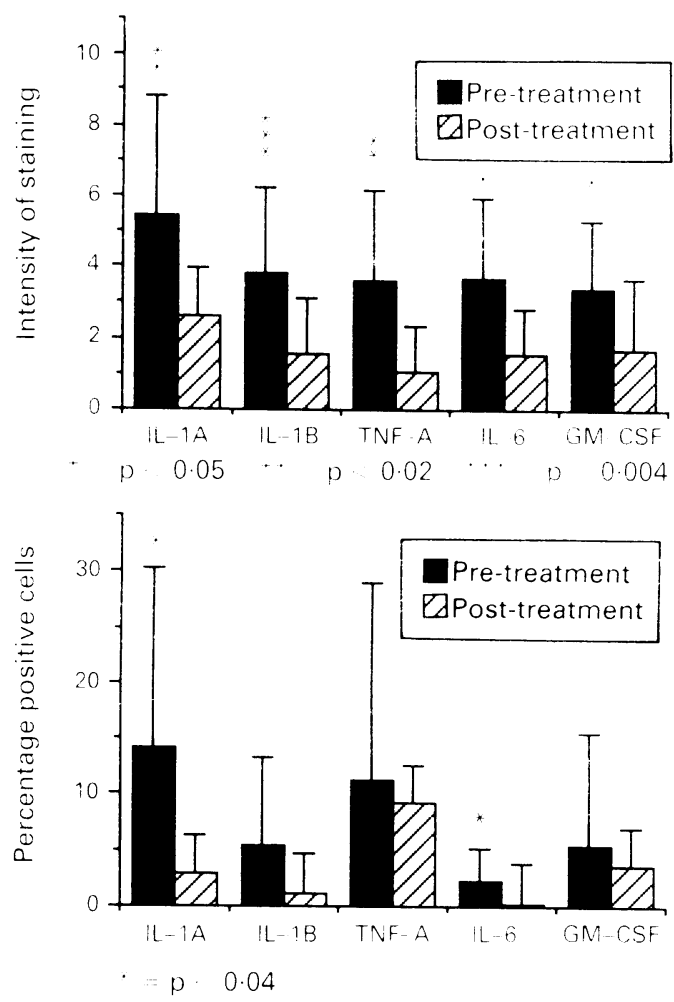

Figure 4 Measurement of the crokines intertiukm-1 alpha (IL,-1A), interleukin-1 beta (II,-1B), tumoul necrosis factor alpha $\left(T N F_{-}-A\right)$, interleukin-6 (IL-6) and granulocyte macrophage-colony stimulating factor (GM-CSF) in the comnectice tissue areas. Upper pand: intensity of staining; lower pand: perentage of positnet. staining cells.

and reversed when untreated MONOs are added back. ${ }^{23}$ Gold has a direct effect on MONO functions which are acquired during differentiation. ${ }^{12} 2420$ Gold inhibits the loss of peroxidase activity and the ability of $\mathrm{MONO}$ to spontaneously produce the second complement component (C2), to lyse chicken erythrocytes and to kill certain nucleated target cells. Gold inhibits the stimulation of MONO $\mathrm{C} 2$ production by $\gamma$-interferon and the markers of monocytic differentiation in HL-60 cells. Haynes et al ${ }^{2 i}$ showed that several gold thiolates used in the treatment of RA inhibit the lymphoproliferative activity of human IL-1 as measured by the lymphocyte activating factor assay.

In clinical studies, levels of circulating IL-1 $\beta$ and IL- $1 \alpha$ in patients with RA have been correlated with clinical disease activity,,$^{2 *} 2^{\prime \prime}$ and the levels of IL-6 with ESR, rheumatoid factor and CRP. ${ }^{30}{ }^{31}$ A lower percentage of $\mathrm{IL}-1 \alpha$ positive cells was detected in the peripheral blood of patients receiving parenteral gold. ${ }^{29}$

The description of a naturally occurring IL-1 ra $^{32}{ }^{34}$ suggests that the body mounts its own response to inflammation. IL- $1 \beta$ and IL-1 ra are separately regulated during monocyte differentiation. IL- $1 \beta$ is produced by CD14+ $\mathrm{MONOs}^{35}$ and IL-1 ra by human MONOs cultured on a substrate of immune complexes or adherent IgG. ${ }^{36}$ IL-1 ra has been detected in RA synovial fluid $^{37}$ and in SM by immunoperoxidase and in situ hybridisation techniques. ${ }^{38}$ IL-1 ra competes with $\mathrm{IL}-1$ for the occupancy of the IL-1 cell surface receptors 
but cannot trigger the cellular reponses typical of IL-1. ${ }^{39}$ In adition, it blocks the production of IL-1 induced IL-1, TNF and IL-6 production from human peripheral blood mononuclear cells as well as from purified MONOs. ${ }^{40}$ By inhibiting IL-1 production, gold salts may enhance the IL-1 neutralising effects of IL-1 ra.

Changes in the immunohistological features following the introduction of gold have received very little attention. Previous studies have demonstrated a reduction in the number of infiltrating $\mathrm{T}$ and $\mathrm{B}$ cells at $\operatorname{six}^{9}$ and 12 months. ${ }^{10}$ The clinical relevance of these findings is doubtful as improvement in disease activity occurs earlier. Neither of these studies examined the MACs in the SM. MACs play an important role in the initiation and maintenance of rheumatoid synovitis. They process and present antigens to $T$ cells, can stimulate blood vessel formation ${ }^{41}$ and represent a steady-state population of cells moving from blood vessels to the synovial lining layer. CD14 molecules participate in the adhesion of MONOs to cytokine stimulated endothelial cells ${ }^{42}$ and migrate through the synovium to form the type A lining layer cells. $^{43}{ }^{44}$ Within inflammatory sites, such as the rheumatoid synovium, MONOs are stimulated by cytokines such as IL- 1, TNF- $\alpha$ and GM-CSF to differentiate into MACs, ${ }^{45} 46$ thus survival of MONOs is a critical component to the maturation process. In the absence of IL-1 $\beta$, TNF- $\alpha$, GM-CSF and IFN- $\gamma$ MONOs undergo programmed cell death or apoptosis. ${ }^{47}$ Gold has the capacity to selectively inhibit some MONO functions which are associated with MAC differentiation ${ }^{25}$ and has been shown to inhibit markers of monocytic differentiation in HL-60 cell lines. The unchanged numbers of CD14+ cells throughout the study period suggest continued entry of MONOs into the RA synovial membrane. The reduction in 27E10, a MONO marker of early acute inflammation, at two weeks may be a steroid related effect, but we did not record a rise in RM3/1+ cells which have been shown to increase in vitro following the addition of dexamethasone. ${ }^{4}$ The decrease in $\mathrm{CD} 68+$ MACs at 12 weeks may suggest a failure of maturation of MONOs to MACs as MONOs die by apoptosis if not stimulated by inflammatory cytokines such as IL-1, TNF- $\alpha$ and GM-CSF ${ }^{47}$ It is also possible that by decreasing cytokine production gold salts also reduce endothelial cell adhesiveness for leukocytes ${ }^{48} 49$ and further contribute to the decrease in MONO/MAC numbers within the synovium.

Thus a plausible scenario for the effects of gold salts can be constructed on the basis of these in vivo and in vitro observations. Before gold therapy, CD14+ MONOs enter the rheumatoid synovium by binding to endothelial cells. In the joint, MONOs are activated and release monokines responsible for maintaining cell viability and promoting the maturation of MONOs to MACs. In the presence of gold salts there is a decrease in the endothelial cell adhesiveness resulting in a reduction of
MONO entry into the RA synovium and reduction in cytokine production. In the absence of these monokines MONO viability is not maintained and MAC numbers decrease. In addition, gold accelerates the maturation of the remaining MONOs to MACs. These mature MACs may release IL-1 ra and other unidentified regulators of inflammation which in turn downregulate the inflammatory response by inhibiting cytokine release.

In conclusion, the findings in this study suggest that SAT may interfere with the mechanisms responsible for persistent rheumatoid synovitis by altering MONO/MAC survival, maturation and function such as release of inflammatory monokines.

This study was financed by a core support grant (U9) from Arthritis and Rheumatism of Great Britain and by the special trustees of Guy's Hospital (Bunty Orchard Lisle Trust). MNMRF was in receipt of a travelling fellowship of the Egyptian government.

1 Harris E D Jr. Rheumatoid arthritis. Pathophysiology and implications for therapy. $N$ Engl $\mathcal{f}$ Med 1990; 332: 1277-89.

2 Dreher R. Origin of synovial type A cells during inflammation, an experimental approach. Immunobiology 1982; 161: $232-45$

3 Zwaldo G, Schegel R, Sorg C. A monoclonal antibody to a subset of human monocytes found only in the peripheral blood of inflammatory tissues. F Immunol 1986; 137: 512-8.

4 Zwaldo G, Voegeli R, Osthoff K S, Sorg C. A monoclonal antibody to a novel differentiation antigen on human macrophages associated with the down-regulatory phase macrophages associated with the down-regulatory phase of the in $295-304$.

5 Arend W P, Joslin F G, Thompson R C, Hannum C H. An IL-1 inhibitor from human monocytes. Production and characterisation of biologic properties. F Immunol 1989; 143: 1851-8.

6 Roux-Lombard P, Modoux P C, Dayer J M. Production of interleukin-1 (IL-1) and a specific IL-1 inhibitor during human monocyte-macrophage differentiation: influence of GM-CSF. Cytokine 1989; 1: 45-51.

7 Smith R J, Chin J E, Sam L M, Justin J M. Biologic effects of an interleukin-1 receptor antagonist protein on interleukin-1-stimulated cartilage erosion and chondrocyte responsiveness. Arthritis Rheum 1991; 34: 78-83.

8 Champion G D, Graham G G, Ziegler J B. The gold complexes. Baillere's Clinical Rheumatology 1990; 4,3: 491-534.

9 Walters M T, Smith J L, Moore K, Evans P R, Cawley M I D. An investigation of the action of disease modifying antirheumatic drugs on the rheumatoid synovial membrane: reduction in $T$ lymphocyte subpopulations and HLA-DP and DQ antigen expression after gold or penicillamine therapy. Ann Rheum Dis 1987; 46: 7-16.

10 Rooney M, Whelan A, Feighery C, Bresnihan B. Changes in lymphocyte infiltration of the synovial membrane and the clinical course of rheumatoid arthritis. Arthritis Rheum 1989; 32: 361-9.

11 Soden M, Rooney M, Whelan A, Feighery C, Bresnihan B. Immunohistologic analysis of the synovial membrane Immunohistologic analysis of the synovial membrane seeking predictors of the clinical course
arthritis. Ann Rheum Dis 1991; 50: 673-6.

12 Littman B H, Carlson P L, Loose L D, Sanders K M. Effect of gold sodium thiomalate and tendinap sodium (CP-66, 248-2) on a model of macrophage differentiation using HL-60 cells. Arthritis Rheum 1990; 33: 29-36.

13 Evans G F, Zuckerman S H. Pharmacologic modulation of TNF production endotoxin stimulated macrophages: in vitro effects of auranofin and other chrysotherapeutic compounds. Agents Actions 1989; 26: 329-4.

14 Arnett F C, Edworthy S M, Bloch D A, et al. The American Rheumatism Association 1987 revised criteria for the classification of rheumatoid arthritis. Arthritis Rheum 1988; 31: 315-24.

15 Corkill M M, Kirkham B W, Chicanza I C, Gibson T, Panayi G S. Intramuscular depot methylprednisolone Panayi G S. Intramuscular depot methylprednisolone
induction chrysotherapy in rheumatoid arthritis: a 24 induction chrysotherapy in rheumatoid arthritis: a 24
week randomised controlled trial. Br $\mathcal{F}$ Rheumatol 1990; week randomi
29: $274-9$.

16 Ritchie D M, Boyle J A, McInnos J M, et al. Clinical studies with an articular index for the assessment of joint tenderness in patients with rheumatoid arthritis. $Q \mathcal{F ~ M e d}$ 1968; 37: 393-406.

17 Hsu S M, Ree H J. Self sandwich method: an improved immunoperoxidase technic for the detection of small amounts of antigen. Am $\mathcal{f}$ Pathol 1980; 4: 32-40. 
$18 \mathrm{Hsu}$ S M, Raine L, Fanger H. Use of avidin-biotin peroxidase complex (ABC) in immunoperoxidase techniques: a comparison between $\mathrm{ABC}$ and unlabelled antibody (PAP) procedures. F Histochem Cytochem 1981 29: 588-90.

19 Thorpe R, Wadh W A, Glearing A J H, Mahon B, Poole S. Sensitive specific immunoradiometric assay for human interleukin alpha. Lymphokine Res 1988; 7: 119-24.

20 Boraschi D, Volpini G, Villa L, et al. A monoclonal antibody to the Interleukin-1 beta peptide $163-171$ blocks
adjuvanticity but not pyrogenicity of IL-1 $\beta$ in vivo. adjuvanticity but not pyro

21 Zenke G, Strittmatter U, Tees R, et al. A cocktail of three monoclonal antibodies significantly increases the sensitivity of an enzyme immunoassay for human granulocyte macrophage colony stimulating factor. f Immunol 1991; 12: 185-206.

22 Hirano $T$, Matsuda $\mathrm{K}$, Hosoi K, Okano A, Matsui $\mathrm{H}$, Kishimoto $\mathrm{T}$. Absent anti-viral activity in recombinant $\mathrm{B}$ cell stimulatory factor-2 (Bsf-2). Immunol Lett 1988; 17: 41-5.

23 Lipsky $P$ E, Ziff $M$. Inhibition of antigen and mitogeninduced human lymphocyte proliferation by gold induced human lymphocyte proliferation

24 Littman B H, Schwartz P. Gold inhibition of the production of the second complement component by lymphokinestimulated human monocytes. Arthritis Rheum 1982; 25: 288-96.

25 Littman B H, Schwartz P. Effects of gold sodium thiomalate on functional correlates of human monocyte maturation. Arthritis Rheum 1985; 28: 1384-92.

26 Sanders K M, Carlson P L, Littman B H. Effects of gold sodium thiomalate on interferon stimulation of $\mathrm{C} 2$ synthesis and HLA-DR expression by human monocytes. Arthritis Rheum 1987; 30: 1032-9.

27 Haynes D R, Garrett I R, Whitehouse $M$ W, VernonRoberts B. Do gold drugs inhibit interleukin-1? Evidence for an in vitro lymphocyte activating factor assay. for an in vitro lymphocyte

28 Eastgate J A, Symons J A, Wood N C, Grinlinton F M, di Giovine F S, Duff G W. Correlation of plasma interleukin-1 levels with disease activity in rheumatoid arthritis. Lancet 1988; ii: 706-9.

29 Barkley D E, Feldman M, Maini R N. Cells with dendritic morphology and bright IL- $1 \alpha$ staining circulate in blood of patients with rheumatoid arthritis. Clin Exp Immunol 1990; 80: 25-31

30 Dasgupta B, Corkill M, Kirkham B, Gibson T, Panayi G S. Serial estimation of interleukin-6 as a measure of systemic disease in rheumatoid arthritis. 7 Rheumatol 1991; 91: 22-5.

31 Houssiau F A, Devogelaer J P, van Damme J, Nagant C, van Snick J. Interleukin- 6 in synovial fluid and serum of patients with rheumatoid arthritis and other inflammatory arthritides. Arthritis Rheum 1988; 31: 784-8.

32 Balavoine J F, de Rochemonteix B, Williamson $\mathrm{K}$ Seckinger P, Cruchaud A, Dayer J M. Prostaglandi E2 and collagenase production by fibroblasts and synovial cells is regulated by urine-derived human interleukin-1 and inhibitor(s). F Clin Invest 1986; 78 $1120-4$.
33 Seckinger P, Lowenthal J W, Williamson K, Dayer J M, MacDonald H R. A urine inhibitor of interleukin-1 activity that blocks the ligand binding. $\mathcal{F}$ Immunol 1987 139: 1546-9.

34 Arend W P, Joslin F G, Thompson R C, Hannum C H. An Il-1 inhibitor from human monocytes. Production and characterisation of biologic properties. F Immunol 1989 ; 143: $1851-8$.

35 Wood N C, Dickens E, Symons J A, Duff G W. In situ hybridization of interleukin-1 in CD14 positive cells in rheumatoid arthritis. Clin Immunol Immunopathol 1992; 62: 295-300.

36 Arend W P, Joslin F G, Massoni R J. Effects of immune complexes on production by human monocytes of interleukin-1 or an interleukin-1 inhibitor. 7 Immunol $1985 ; 134: 3868-75$

37 Malyak M F, Joslin F G, Verdeber E L, Eisenberg S P, Arend W P. IL-1 ra ELISA: Reduction and alkylation of synovial fluid eliminates interference by IgM rheumatoid factors. F Immunol Methods 1991; 40: 281-8.

38 Firestein G S, Berger A E, Tracey D E, et al. IL-1 receptor antagonist protein production and gene expression in rheumatoid arthritis and osteoarthritis synovium. rheumatoid arthritis and

39 Dinarello C A, Thompson R C. Blocking IL-1: interleukin1 receptor antagonist in vivo and in vitro. Immunol Toda 1991; 12: 404-10.

40 Granowitz E V, Porat R, Mier W, et al. Pharmacokinetics, safety and immunomodulatory effects of human recombinant interleukin-1 receptor antagonist in health humans. Cytokine 1992; 4: 353-60.

41 Koch A E, Poverini P J, Leibovich S J. Stimulation of neovascularisation by human rheumatoid synovial tissue macrophages. Arthritis Rheum 1986; 29: 471-9.

42 Beekhuizen H, Blokland I, Corsel-van Tilburg, Koning F, van Furth R. CD14 contributes to the adherence of human monocytes to cytokine stimulated endothelial cells. F Immunol 1991; 147: 3761-7.

43 Mapp P I, Revell P A. Ultrastructural characterisation of macrophage (type A) cells in the synovial lining. $B r \mathscr{F}$ 8; 8: $171-6$

44 Revell P A. Synovial lining cells. Rheumatol Int 1989; 9 49-51

45 Mangan D F, Welch G R, Wahl S M. Lipopolysaccharide, tumour necrosis factor- $\alpha$, IL- $1 \beta$ prevent programmed cell death (apoptosis) in human peripheral blood monocytes. f Immunol 1991; 146: 1541-6.

46 Becker S, Warren K M, Haskill S. Colony stimulating factor induced monocyte survival and differentiation into macrophages in serum free culture. $f$ Immunol 1987; 139: 3703-9.

47 Mangan D F, Wahl S $M$. Differential regulation of programmed cell death (apoptosis) by chemotactic factors programmed cell death (apoptosis) by chemotactic factors 3408-12.

48 Cavender D E, Haskard D O, Benedict J, Ziff $M$ Interleukin-1 increases the binding of human $\mathrm{B}$ and $\mathrm{T}$ lymphocytes to endothelial cell monolayer. 7 Immunol 1986; 136: 203-7.

49 Cavender D E, Saegusa Y, Ziff M. Stimulation of endothelial cell binding of lymphocytes by tumour necrosis factor. F Immunol 1987; 139: 1855-60. 